population of Pakistan". Pak J Med Sci, 2019, 35(1):50-54.

4. Jai Rup Singh, Sarla Banerjee. "Normal value for interpupillary, inner canthal and outer canthal distances in an Indian population". Human Heredity, 1983, 33(5):326-328.

5. Murphy KW., Laskin DM. "Intercanthal and interpupillary distance in the black population". Oral Surg Oral Med Oral Pathol, 1990, 69:676-80.
6. Osuobeni EP, Al-ibraheem AM. "Ocular and facial dimensions of male Arab children". J Am Optom Assoc, 1993, 64:717-7.

7. Pryor HB. "Objective measurement of interpupillary distance". Pediatrics, 1969, 44:973-977.

8. Razavi ME, Jalalifar S. "Correlation between Interpupillary and Inner-Outer Intercanthal Distances in Individuals Younger than 20". ] Ophthalmic Vis Res, 2008, 3(1):16-22.

\title{
KIẾN THỨC CỦA ĐIỀU DƯỡNG VỀ PHÒNG NGỪA TÉ NGÃ CHO NGƯỜI BỆNH TẠI BỆNH VIỆN ĐA KHOA TỈNH NAM ĐỊNH NĂM 2020
}

\section{TÓM TẮT}

Mục tiêu: Mô tả thực trạng kiến thức của điều dưỡng vềphòng ngừa té ngã cho người bệnh tại Bệnh viện Đa khoa tỉnh Nam Định Đối tượng và phướng pháp nghiên cứu: Nghiên cứu mô tả cắt ngang vớl sư tham gia của 170 điều dưỡng trực tiếp chăm sóc người tại các khoa lâm sàng Bệnh viện Đa khoa tỉnh Nam Định từ tháng 12/2019 đến tháng 6/2020. Kết quả: Đa số điều dưỡng là nữ giới $(81,8 \%)$ và có thâm niên công tác dưới 10 năm chiếm tỷ lê cao nhất (51,8\%). Điều dưỡng có số người bệnh phải chăm sóc trung bình/ ngày dưới 10 người bểnh là $(58,8 \%)$ và vẫn còn $34,7 \%$ chưa tham gia các lớp đào tạo về phòng ngừa té ngã. Tỷ lệ điều dưỡng có kiến thức về phòng ngừa té ngã cho người bệnh ở mức đạt là $56,5 \%$. Kết luân: Mức độ kiến thưư phòng ngửa té ngã cho người bệnh của điều dưỡng chưa thực sự cao. Kết quả nghiên cứu cho thây sự cần thiết phải củng cố kiến thức cho điêu dưỡng về dự phòng té ngã cho người bênh.

Tứ khoá: Kiến thức, phòng ngừa té ngã, người bệnh, điều dưỡng

\section{SUMMARY}

NURSES' KNOWLEDGE ON FALL PREVENTATION FOR PATIENTS AT

\section{NAMDINH GENERAL HOSPITAL 2020}

Objective: Describe the nurses' knowledge on fall preventation for patients at Namdinh General Hospital. Subjects and methods: A cross-sectional study on 170 nurses who directly care for patients at clinical units at Namdinh General Hospital during 12/2019 and 6/2020. Results: The majority of nurses are women $(81.8 \%)$ and have been working for less than 10 years, accounting for the highest percentage (51.8\%). The average number of nurses taking care of less than

${ }^{1}$ Trường ĐH Điều dưỡng Nam Định Chiu trách nhiêm chính: Hoàng Thị Minh Thái Email: minhthai82nd@gmail.com Ngày nhận bài: 2/1/2021

Ngày phản biện khoa học: 1/2/2021

Ngày duyệt bài: 3/3/2021
Hoàng Thị Minh Thái ${ }^{1}$, Đinh Thị Thu Hằng ${ }^{1}$, Phạm Thị Bích Ngọc ${ }^{1}$, Vũ Thị Lài , Vũ Thị Én'

10 patients per day is (58.8\%) and $34.7 \%$ have not yet attended training courses on falls prevention. The percentage of nurses, who had sufficient knowledge, was $56,5 \%$. Conclusion: The nurses' knoledge and practice on fall preventation for patients were limited. Therefor, nurse should be provided knowldge on fall preventation for patients.

Keywords: Knowldge, fall Preventation for patients, nurse, patient.

\section{I. ĐẶT VẤN ĐỀ}

Té ngã là một trong sáu sự cố y khoa được phân loại dựa vào đặc điểm chuyên môn theo Hiệp hội An toàn người bệnh Thế giới. Mỗi năm có khoảng 37,3 triệu ca té ngã cần đến sự chăm sóc y tế, dẫn đến 646.000 ca tử vong do té ngã trên toàn cầu. Té ngã là nguyên nhân đứng hàng thứ hai gây tử vong do thương tích không chủ ý sau tai nạn giao thông đường bộ và thường gặp ở những người từ 65 tuổi trở lên. Tại Việt Nam, theo một thống kê tại Bệnh viện Đại học Y Dược thành phố Hồ Chí Minh năm 2017, té ngã chiếm 92,31\% trong các sự cố $Y$ khoa thường có trong bệnh viện [1]. Té ngã mang lại hậu quả to lớn về không chỉ đến sức khỏe mà còn tác động xấu đến chi phí điều trị cho người bệnh. Với đặc thù nghề nghiệp của mình, Điều dưỡng có thời gian chăm sóc người bệnh so với các đối tượng khác cao hơn nên việc đảm bảo an toàn cho người bệnh nói chung và phòng ngừa té ngã cho người bệnh nói riêng là nhiệm vụ quan trọng. Thông tư số 19/2013/TT-BYT của Bố $Y$ tế đã nêu rõ phòng ngừa người bệnh té ngã là một trong những nội dung khi thiết lập chương trình và xây dựng các quy định cụ thể bảo đảm an toàn người bệnh và nhân viên y tế.

Tại Nam Định, trong những năm qua, ngành Y tế Nam Định đã thực hiện các giải pháp nhằm nâng cao chất lượng dịch vụ khám chữa bệnh. Tuy nhiên, các đánh giá về công tác phòng ngừa 
té ngã cho người bệnh tại các bệnh viện nói chung và tại Bệnh viện Đa khoa tỉnh Nam Định nói riêng còn chưa nhiều và chưa đầy đủ. Để có được số liệu cụ thể về thực trạng kiến thức của điều dưỡng trong việc phòng ngừa té ngã cho người bệnh cũng như cung cấp bằng chứng về hoạt động đảm bảo an toàn người bệnh tại bệnh viện, chúng tôi thực hiện đề tài: Kiến thức của điều dưỡng về phòng ngừa té ngã cho người bệnh tại Bệnh viện Đa khoa tỉnh Nam Định năm 2020" với mục tiêu mô tả thực trạng kiến thức của điều dưỡng về phòng ngửa té ngã cho người bệnh tại Bệnh viện Đa khoa tỉnh Nam Định năm 2020.

\section{II. ĐỐI TƯợNG VÀ PHƯƠNG PHÁP NGHIÊN CỨU}

2.1. Đối tượng nghiên cứu. Nghiên cứu thực hiện từ tháng 02/2020 đến tháng 5/2020 trển 170 điều dưỡng đang công tác tại các khoa lâm sàng Bệnh viện Đa khoa tỉnh Nam Định. Lựa chọn điều dưỡng trực tiếp chăm sóc người bệnh tại các khoa lâm sàng của Bệnh viện, có thời gian làm việc từ 1 năm trở lên (đủ thời gian để trải nghiệm thực hành chăm sóc về chuyên môn nói chung và phòng ngừa té ngã cho người bệnh nói riêng) và đồng ý tự nguyện tham gia nghiên cứu, không bị tác động của bất cứ yếu tố ép buộc nào. Loại trừ các điều dưỡng vắng mặt trong khoảng thời gian thu thập số liệu vì những lý do khách quan hoặc chủ quan như đi học tập; công tác, nghỉ thai sản; ốm đau v.v...

2.2. Phương pháp nghiên cứu. Thiết kế nghiên cứu mô tả cắt ngangchọn toàn bộ điều dưỡng đáp ứng tiêu chuẩn chọn mẫu. Nghiên cứu sử dụng bộ câu hỏi tự điền để đánh giá kiến thức về phòng ngừa té ngã của điêu dưỡng gồm 2 phần: Phần A: các thông tin chung về đối tượng nghiên cứu; Phần $\mathrm{B}$ : kiến thức về phòng ngừa té ngã cho người bệnh.

Bộ công cụ đánh giá kiến thức về phòng ngừa té ngã gồm 24 câu hỏi với các đáp án đúng và sai. Bộ công cụ này được xây dựng dựa trên công cụ "Fall prevention knowledge tests" của tác giả Patricia C. Dykes và các cộng sự công bố năm 2019 [5], được dịch ra tiếng Việt và đánh giá độ tin cậy cho kết quả hệ số tương quan giữa hai lần phỏng vấn $>0.7$. Sử dụng phương pháp gán điểm để đánh giá kiến thức của đối tượng, trả lời mối ý đúng là 1 điểm, sai 0 điểm. Tổng số ý trả lời đúng là 24 tương ứng với tổng số điểm là 24 điểm. Kiến thức của điêuu dưỡng được phân thành các nhóm như sau:

Bảng 1: Tiêu chí phân loại kiến thức đối tượng nghiên cứu

\begin{tabular}{|c|c|c|}
\hline $\begin{array}{c}\text { Khoảng } \\
\text { điểm }\end{array}$ & Mức độ & $\begin{array}{c}\text { Phân } \\
\text { loại }\end{array}$ \\
\hline$<7$ & Chưa có kiến thức & \multirow{2}{*}{ Chưa đạt } \\
\hline $7-<13$ & Kiến thức kém & \\
\hline $13-<19$ & Kiến thức trung bình & \multirow{2}{*}{ Đạt } \\
\hline $19-24$ & Kiến thức tốt & \multicolumn{2}{|c|}{} \\
\hline
\end{tabular}

\section{KẾT QUẢ NGHIÊN CỨU}

3.1. Một số thông tin chung về đối tượng nghiên cứu. Kết quả cho thây nhóm tuổi đời của điều dưỡng viên tham gia nghiên cứu từ 3145 tuổi cao nhất $(61,7 \%)$, ở nhóm tuổi dưới 31 có tỷ lệ nữ giới cao nhất $(86,3 \%)$. Đa số điều dưỡng là nữ giới $(81,8 \%)$ và có thâm niên công tác dưới 10 năm chiếm tỷ lệ cao nhất $(51,8 \%)$. Điều dưỡng có trình độ trung cấp chiếm tỷ lệ cao nhất $(36,5 \%)$, sau đó là độ đại học $(33,5 \%)$ và cao đẳng (30\%). Điều dưỡng có số người bệnh phải chăm sóc trung bình/ ngày dưới 10 người bệnh là $(58,8 \%)$, trên 10 người bệnh/ ngày $(41,2 \%)$. Vẫn còn $34,7 \%$ chưa tham gia các lớp đào tạo về phòng ngừa té ngã.

3.2. Thực trạng kiến thức của điêu dưỡng về phòng ngừa té ngã cho người bệnh

Bảng 2. Phân chia mức độ kiến thức về phòng ngừa té ngã của điều dưỡng theo từng nhóm kiến thức $(n=170)$

\begin{tabular}{|c|c|c|c|c|}
\hline \multirow[b]{2}{*}{$\begin{array}{c}\text { Mức đô kiến } \\
\text { thứcc }\end{array}$} & \multicolumn{4}{|c|}{ Tỷ lệ \% theo nhóm kiến thức } \\
\hline & $\begin{array}{c}\text { Yếu tố } \\
\text { nguy } \\
\text { cơ }\end{array}$ & $\begin{array}{c}\text { Đánh } \\
\text { giá nguy } \\
\text { cơ }\end{array}$ & $\begin{array}{c}\text { Dự } \\
\text { phòng }\end{array}$ & Quản lý \\
\hline $\begin{array}{l}\text { Chưa có kiến } \\
\text { thức }\end{array}$ & 0,0 & 17,6 & 1,8 & 4,1 \\
\hline $\begin{array}{l}\text { Kiến thức } \\
\text { kém }\end{array}$ & 44,7 & 75,9 & 44,1 & 64,2 \\
\hline $\begin{array}{l}\text { Kiến thức } \\
\text { trung bình }\end{array}$ & 21,8 & 5,3 & 44,7 & 27,6 \\
\hline Kiến thức tốt & 33,5 & 1,2 & 9,4 & 4,1 \\
\hline
\end{tabular}

Bảng 2 cho thấy nhóm yếu tố nguy cơ có mức độ kiến thức tốt cao nhất (33,5\%), nhóm đánh giá nguy cơ có mức độ kiến thức kém $(75,9 \%)$

Bảng 3. Phân loại kiến thức về té ngã của điều dưỡng theo từng nhóm

\begin{tabular}{|c|c|c|}
\hline \multirow{2}{*}{$\begin{array}{c}\text { Nhóm kiến } \\
\text { thức }\end{array}$} & \multicolumn{2}{|c|}{ Tỷ lệ \% theo phân loại } \\
\cline { 2 - 3 } & Không đạt & Đạt \\
\hline Yếu tố nguy cơ & 44,7 & 55,3 \\
\hline Đánh giá nguy cơ & 93,5 & 6,5 \\
\hline Dự phòng & 45,9 & 54,1 \\
\hline Quản lý & 68,3 & 31,7 \\
\hline
\end{tabular}

Kết quả bảng 3 cho thây tỷ lệ đối tượng có điểm ở nhóm đánh giá nguy cơ hầu như ở mức không đạt $(93,5 \%)$, nhóm yếu tố nguy cơ có mức đạt cao nhất $(55,3 \%)$. 
Bảng 4. Phân loại kiên thức chung của điều dưỡng về té ngã ( $n=170)$

\begin{tabular}{|c|c|c|c|c|}
\hline $\begin{array}{l}\text { Mứuc } \\
\text { điểm }\end{array}$ & $\begin{array}{c}\text { Số } \\
\text { Iượng }\end{array}$ & $\begin{array}{l}\text { Tỷ lề } \\
\%\end{array}$ & Mức độ & $\begin{array}{c}\text { Phân } \\
\text { loại }\end{array}$ \\
\hline $0-6,99$ & 0 & 0,0 & $\begin{array}{c}\text { Chưa có kiến } \\
\text { thức }\end{array}$ & \multirow{2}{*}{$\begin{array}{c}\text { Chưa } \\
\text { đạt }\end{array}$} \\
\hline $7,0-12,99$ & 74 & 43,5 & $\begin{array}{l}\text { Kiến thức } \\
\text { kém }\end{array}$ & \\
\hline $\begin{array}{l}13,0- \\
18,99\end{array}$ & 96 & 56,5 & $\begin{array}{l}\text { Kiến thức } \\
\text { trung bình }\end{array}$ & \multirow[t]{2}{*}{ Đạt } \\
\hline $19,0-24,0$ & 0 & 0,0 & Kiến thức tốt & \\
\hline
\end{tabular}

Qua kết quả ở bảng 4, điều dưỡng có kiến thức chung đạt chưa cao với tỷ lệ $56,5 \%$.

\section{BÀN LUÂ̂N}

Khảo sát kiến thức chung của điều dưỡng về phòng té ngã, nghiên cứu của chúng tôi cho thấy có $56,5 \%$ điều dưỡng ở mức đạt. Tỷ lệ này cao hơn so với nghiên cứu năm 2019 của Nguyễn Thị Thúy $(38,3)$ [4] và của Lee In Kyoung $(45,5 \%)$ [8]; điều dưỡng có kiến thức không đạt chiếm tỳ lệ $(43,5 \%)$ thấp hơn nghiên cứu của Nguyễn Thị Thanh Hương về kiến thức đối với sự cố y khoa $(77,3 \%)$ [3] nhưng lại cao hơn nghiên cứu năm 2015 của Hesti Oktaviani tại một bệnh viện ở thành phố Surakarta, Indonesia $(30,8 \%)$ [7]. Sự chênh lệch về tỷ lệ nói trên khi so sánh giữa nghiên cứu trong nước và nước ngoài phản ánh mối quan tâm về vấn đề an toàn người bệnh nói chung và phòng ngừa té ngã nói riêng giữa Việt Nam và các nước vẫn còn một khoảng cách. Mặc dù trong những năm gần đầy ngành y tế nước ta đã chú trọng đến các chính sách vĩ mô về an toàn người bệnh cũng như cải tiến chương trình đào tạo điều dưỡng ở các trường chuyên nghiệp. Đối với điều dưỡng đang công tác tại các cơ sở y tế, kết quả trên cho thấy mức độ quan tâm tới an toàn người bệnh đặc biệt là công tác phòng ngừa té ngã của điều dưỡng cần được cải thiện.

Kiến thức về phòng ngừa té ngã cho người bệnh bao gồm 4 nội dung: yếu tố nguy cơ, đánh giá nguy cơ, dự phòng té ngã và quản lý té ngã. Trong nội dung kiến thức vềyếu tố nguy cơ té ngã của người bệnh nghiên cứu của chúng tôi cho thấy có $44,7 \%$ điều dưỡng có mức kiến thức kém. Đây có thể đã là nguyên nhân dẫn đến người bệnh không được giám sát chặt chẽ trong phòng ngừa té ngã. Về nội dung đánh giá nguy cơ té ngã, kết quả nghiên cứu chỉ ra rằng đa số điều dưỡng $(93,5 \%)$ có mức điểm không đạt và cao nhất trong 4 nội dung kiến thức đánh giá. Như thế số người bệnh có nguy cơ té ngã có thể đã bị bỏ qua không được đánh giá nguy cơ té ngã và sẽ không được phòng ngừa té ngã trong kế hoạch chăm sóc người bệnh nói chung. Với kiến thức về nội dung dự phòngté ngã có $44,1 \%$ điều dưỡng có mức kiến thức kém. Cụ thể 3,5\% điều dưỡng trả lời rằng nguy cơ té ngã của người bệnh do các vấn đề về sinh lý có thể được ngăn chặn bằng cách cung cấp một môi trường an toàn; ví dụ: đường thông thoáng đến phòng tắm, phòng không lộn xộn, giâyy dép tốt. 7,1\% điều dưỡng cho là nên lắp đặt hệ thống báo động tại giường bệnh và ghế cho tất cả các bệnh nhân sàng lọc dương tính có nguy cơ bị ngã. Sô lượng nội dung kiến thức đúng về dự phòng té ngã mà đối tượng có thể cùng lúc trả lời được ở $4 / 6$ câu đúng là $44,7 \%$, đúng cả 6 câu chỉ có $1,2 \%$. Kiến thức đúng của điều dưỡng về quản lý té ngã, nghiên cứu của chúng tôi cho thấy có $87,6 \%$ điều dưỡng đã trả lời đúng rằng khi có kế hoạch phòng ngừa té ngã chính xác và được thực hiện, việc té ngã được ngăn chặn ở khoảng $75 \%$ người bệnh có nguy cơ. 79,4\% Điều dưỡng viên cần phải quản lý tốt nhóm người bệnh có nhiều vấn đề y tế thường phải dùng nhiểu loại thuốc và yêu cầu các biện pháp can thiệp cá nhân nhắm vào cả triệu chứng và tác dụng phụ của thuốc. Số lượng nội dung kiến thức đúng về quản lý té ngã mà đối tượng có thể cùng lúc trả lời được ở $3 / 6$ câu đúng là $41,8 \%$, đúng cả 6 câu chỉ có $0,6 \%$.

Theo học thuyết về nhận thức xã hội của Albert Bandura, điêu dương là sự hợp tác với người bệnh để tạo điều kiện thuận lợi nhất cho sức khỏe. Một trong những vai trò của điêu dưỡng là giúp người bệnh học cách tự chăm sóc bản thân từ đó có thể phòng ngừa được bệnh tật và giúp bảo đảm sức khỏe tốt hơn. Các hoạt động phòng ngừa té ngã cho người bệnh của điêu dưỡng là hoạt động xuyên suốt ngay từ khi người bệnh nhập viện cho đến lúc họ được xuất viện. Do đó khi chăm sóc người bệnh tại bệnh viện, người điều dưỡng cần có kiến thức về phòng ngừa té ngã để từ đó có những biện pháp phòng ngừa để đảm bảo an toàn cho người bệnh.

\section{KẾT LUÂN}

Đa số điều dưỡng là nữ giới $(81,8 \%)$ và có thâm niên công tác dưới 10 năm chiếm tỷ lệ cao nhất $(51,8 \%)$. Điều dưỡng có số người bệnh phải chăm sóc trung bình/ ngày dưới 10 người bệnh là $(58,8 \%)$ và vẫn còn $34,7 \%$ chưa tham gia các lớp đào tạo về phòng ngừa té ngã.

Kiến thức của điều dưỡng về phòng ngừa té ngã cho người bệnh ở mức độ trung bình. Tỷ lệ điêu dưỡng có kiến thức đạt là $56,5 \%$. 


\section{KHUYẾN NGH!}

Kết quả nghiên cứu cho thấy sự cần thiết phải củng cố kiến thức cho điều dưỡng về phòng ngừa té ngã cho người bệnh.

\section{TÀI LIẸU THAM KHẢO}

1. Bênh viện Đại học $Y$ dược Thành phố Hồ Chí Minh. An toàn người bênh, Bản tin An toàn người bệnh, Thành Phố Hồ Chí Minh. 2017.

2. Bềnh viện Đại học Y Dược Thành phố Hồ Chí Mỉnh. Qưy trình phòng ngứa và xử trí té ngã đối với ngưới bệnh nội trú;2016; 8-9.

3. Nguyển Thị Thanh Hương. Khảo sát thái độ, kiến thức đối với sự cố y khoa không mong muốn của Điều dưỡng, Hộ sinh tai Bênh viên Đa khoa trung ương Thái Nguyên. Hội nghị Khoa học Công nghể tuổi trẻ và Nghiệm thu đề tài $K H \& C N$. Trường Đại học Y dược Thái Nguyên 2016; 62-65.

4. Nguyễn Thị Thúy. Thay đổi kiến thức, thực hành về phòng ngừa té ngã cho người bệnh của Điều dưỡng viên tai một số khoa lâm sàng Bênh viên đa khoa tỉnh Hà Nam năm 2019. Luận văn Thạc sỹ, Đại học Điều dưỡng Nam Định; 2019.

5. Dykes Patricia C.et al. Development and Validation of a Fall Prevention Knowledge Test, J Am Geriatr Soc 2019; 67(1), 133-138.

6. Gray-Micelli Deanna and A. Quigley Patricia. Nursing Standard of Practice Protocol: Fall Prevention, Springer Publishing Company 2012.

7. Hesti Oktaviani, S Dwi Sulisetyawati and Rufaida Nur Fitriana. Hubungan pengetahuan dengan kepatuhan perawat dalam pelaksanaan standar prosedur operasional pencegahan resiko jatuh pasien di rumah sakit panti waluyo surakarta. STIKES Kususma Husada; 2015

8. Lee In Kyoung and Choi Ya Jun. Factors Associated with NursesActivities for Hospital Fall Prevention. The Korean Journal of Rehabilitation Nursing 2013; 16(1), 55-62.

\section{TUÂN THỦ ĐIỀU TRI KHÔNG DÙNG THUỐC CỦA NGƯỜI BÊ̂NH TĂNG HUYẾT ÁP TẠI KHOA TIM MẠCH PHÒNG KHÁM ĐA KHOA HOÀN MỸ SÀI GÒN}

\section{TÓM TẮT}

Mục tiêu: Ghi nhận tỉ lệ tuân thủ điều trị không dùng thuốc của người bệnh đang điều trị ngoại trú tăng huyết áp tại Phòng khám đa khoa Hoàn Mỹ Sài Gòn. Phương pháp nghiên cứu: Nghiên cứu cắt ngang mô tả. Ngưới bệnh được chọn ngẫu nhiên; được phỏng vấn trực tiếp và thu thầp số liệu theo bảng thu thập số liệu soạn sẵn. Mức độ tuân thủ điều trị không dừng thuốc được tổng hợp dựa trên thang điểm Dietary Guidelines for Disease Management. Kêt quả: Trong tổng số 387 bệnh nhân, hầu hết bệnh nhân tuân thủ từ 1 đến 6 trong số 8 khuyến cáo về lối sống có lợi cho sức khỏe. Các hoạt động thể lực, ăn trái cây, ằn rau được thực hiện nhiều nhưng đa số chưa đủ tiêu chuẩn lý tưởng. Đặc biệt, còn nhiều người chấm muối khi ăn trái cây hoặc dùng nước chấm trong bữa ăn. Khi được hỏi về tham gia các hoạt động thể dục thể thao, các câu trả lời cho thấy đi bộ là hoạt động thể dục được lựa chọn thực hiện nhiêu nhất $(63.0 \%)$. Có mối liên quan có ý nghĩa thống kê giữa tuân thủ điều trị thay đổi lối sống cao hơn và giới tính nam $(p<0,01)$, trình độ học vấn cao $(p<0,01)$, nhóm bệnh nhân không có bệnh đồng mắc $(p<0,01)$.

\footnotetext{
*Trương Đại học Y khoa Phạm Ngọc Thạch

**Phòng khám Đa khoa Hoàn Mỹ Sài Gòn

Chiu trách nhiệm chính: Trần Đức Sĩ

Email: sitd@pnt.edu.vn

Ngày nhận bài: 3/1/2021

Ngày phản biện khoa học: 29/1/2021

Ngày duyệt bài: 27/2/2021
}

\author{
Trần Đức Sĩ*, Nguyễn Hùng**, \\ Phan Kim M Ỹ
}

Kết luân: Bệnh nhân chủ yếu tuân thủ ở mức trung bình; số tuân thủ tốt nhìn chung là không bằng so với kết quả nghiên cứu của đồng nghiệp khác. Cân phải nâng cao kiến thức và nhận thức của người dân về việc thay đổi lối sống. Nhấn mạnh vai trò của ăn giảm mă̆n vì đây là kiến thức phổ biến nhưng người dân chưa thay đổi về thái độ và hành hành. sống, ăn mặn, tập thể dục.

\section{SUMMARY}

\section{COMPLIANCE WITH LIFESTYLE RECOMMENDATIONS FOR HYPERTENSION IN OUT-PATIENTS AT HOAN MY SAI GON CLINIC}

Aims: To describe the non-drug treatment compliance ratein hypertensive patients at Hoan My Saigon Clinic. Research method: In this descriptive cross-sectional study, we interviewed 387 randomized patients using a prepared questionnaire and also collected clinical data from the clinic's prescription software. Adherence to non-drug therapy was compiled based on the Dietary Guidelines for Disease Management scale. Results: Most of patients complied with 1 to 6 out of 8 healthy lifestyle recommendations. However, they did not meet the ideal standards. Many people used salt when eating fruits or using dipping sauce with meals. When asked about physical activities and sports, walking was the exercise of choice for the most patients (63.0\%). There was a statistically significant relationship between higher adherence to lifestyle changes and gender $(p<0.01)$, high education level $(p<0.01)$ and
Tư khóa: Tăng huyết áp, tuân thủ điều trị, lối 